\title{
Fetomaternal outcome in patients with threatened abortion in the first trimester - An observational study
}

\author{
Mousumi Ghosh ${ }^{1}$, Aparna Khan Mandal ${ }^{2}$, Shelley Seth ${ }^{3}$, Animesh Naskar ${ }^{4}$ \\ ${ }^{1}$ Senior Resident, ${ }^{2,3,4}$ Associate Professor, Department of Obstetrics and Gynaecology, R. G. Kar Medical College and \\ Hospital, Kolkata, West Bengal, India
}

Background: Uterine bleeding in early pregnancy represents a definite threat to developing embryo and is directly proportional to the amount of bleeding. It is associated with an increased risk of poor obstetric and neonatal outcomes such as preterm labor, low birth weight, and premature rupture of membranes (PROM). Aims and Objectives: This study aims to investigate the effect of the first trimester vaginal bleeding on maternal and perinatal outcomes. Materials and Methods: This prospective observational study carried out in a tertiary teaching hospital of Kolkata, between January 2019 and June 2020. Here,190 patients with the first trimester vaginal bleeding were included in the study. Outcome of pregnancy was assessed in the form of obstetrical complications such as placenta previa, PROM, preterm labor, intrauterine fetal death, intrauterine growth retardation (IUGR), and neonatal outcomes such as prematurity, low birth weight, low appearance, pulse, grimace, activity, and respiration, requirement of newborn intensive care unit (NICU) admission, and perinatal death. Results: Our study shows that $116(61.05 \%)$ out of 190 were primi gravida and rest $74(38.95 \%)$ were multigravida. Seventy-five (39.47\%) had missed abortion, $43(22.63 \%)$ patients had incomplete abortion, and $23(12.10 \%$ ) out of 190 patients resulted in complete abortion. About $19.47 \%$ (37 out of $190)$ had viable pregnancy. Six (16.21\%)out of 37 patients had preterm delivery, $4(10.81 \%)$ out of 37 patients had antepartum hemorrhage. Preeclampsia developed in $8.1 \%$ (three out of 37) patients. About 48.64\% (18) delivered vaginally, 45.94\% (17) underwent lower segment cesarean section, and only $2(5.40 \%)$ patients had instrumental delivery(forceps). Regarding neonatal outcome, $5.40 \%$ had early neonatal death, $21.62 \%$ needed NICU admission, $8.10 \%$ suffered from fetal distress, $5.40 \%$ had meconium stained liquor, $8.10 \%$ were IUGR, and $32.43 \%$ had birth weight $<1.5 \mathrm{~kg}$. Conclusion: The first trimester bleeding is a predicting factor for obstetric and perinatal complications during pregnancy.

Key words: Fetomaternal outcome; First trimester bleeding; Threatened abortion
Access this article online

Website:

http://nepjol.info/index.php/AJMS

DOI: 10.3126/ajms.v13i3.41483

E-ISSN: 2091-0576

P-ISSN: $2467-9100$

Copyright (c) 2022 Asian Journal of Medical Sciences

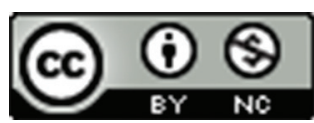

This work is licensed under a Creative Commons Attribution-NonCommercial 4.0 International License.

\section{INTRODUCTION}

Threatened abortion is defined as evident bleeding per vagina without dilation of cervix or cervical dilatation without vaginal bleeding in early period of gestation. Confirmation of diagnosis is done by ultrasonography finding of the presence of fetal heart beat. Uterine bleed in early pregnancy represents a definite threat to developing embryo and is directly proportional to the amount of bleeding. It constitutes a source of anxiety to both the patient and the clinician. Clinical vaginal bleeding during the first trimester is associated with an approximate $5.5-42.7 \%$ riskfor subsequent complete miscarriage. ${ }^{1,2}$ It is associated with an increased risk of poor obstetric outcomes such as preterm labor, low birth weight, and premature rupture of membranes (PROM). The purpose of this study was to investigate the effect of the first trimester vaginal bleeding on maternal and perinatal outcomes. 
Aims and objectives

Our study aims to evaluate the fetomaternal outcome in women presented with threatened abortion in the first 12 weeks of gestation.

\section{MATERIALS AND METHODS}

This is an observational prospective study done at R.G. Kar Medical College and Hospital among patients admitted in the Department of Obstetrics and Gynaecology from January 1, 2019, to June30, 2020, that is, 18 months. From January 2019 up to September 2019, we enrolled the patients for the study and for the next 9 months, that is, from October 2019 to June 2020, we followed up them to study the fetomaternal outcome. Data collection was started after the institutional ethical clearance. One hundred and ninety patients presented with bleeding per vagina with $\leq 3$ months pregnancy, positive pregnancy test and gave consent for study were included by multiphasic sampling method without taking emergency cases who needed immediate surgical interventions such as incomplete and missed abortion, ectopic and molar pregnancy, with a history of abortifacient intake, any local lesions and bleeding disorders, and pregnant women with chronic medical complications.

\section{Ethical clearance}

Ethical clearance had been obtained from review and ethical committee of R.G. Kar Medical College and Hospital.

\section{Sample size}

The study patients were taken from obstetrics and gynecology department between January 2019 and June 2020.Purposive sampling technique was applied for sampling. It had been observed that around 5 patients/ week of threatened abortion came to Obstetrics and Gynaecology Department in RGKMCH. Hence, the study subject for my study was $(5 \times 4 \times 9)=180$. Estimating $10 \%$ dropout $(180+18)$ cases $=198$ cases, but eight patients dropped out. Hence, eventually, our study sample was 190.

\section{Study procedure and data collection}

After admission through Obstetrics and Gynecology emergency in RGKMCH, patient particulars such as parity, gestational age, last menstrual period, and amount of bleeding were taken from indoor bed tickets (BHT). Patients continuing pregnancy were discharged to attend antenatal care outpatient department later on and future outcomes were recorded from records of antenatal cards and BHTs when they were admitted for delivery. Patients contact numbers and addresses were recorded for future correspondence. Neonatal outcomes were recorded from log records, nursery records, and in some cases from newborn intensive care unit (NICU) registers. The patients were followed up until their final outcome. Figure 1 depicts the entire study procedure.

Later, the outcomes of pregnancy were assessed in the form of obstetrical complications such as placenta previa, PROM, preterm labor, intrauterine fetal death (IUFD), FGR, and neonatal outcomes such as prematurity, low birth weight, low appearance, pulse, grimace, activity, and respiration (APGAR), NICU admission, and perinatal death. Maternal data were collected from log book, antenatal records, patient BHTs, and fetal data were taken from neonatal record log books, nursery records, and NICU register. Patients under went all antenatal checkups and investigations such as hemoglobin \%, ABO grouping and Rh typing, fasting blood sugar, postprandial blood sugar high-performance liquid chromatography, thyroid-stimulating hormone, free T4, venereal disease research laboratory, human immunodeficiency virus 1

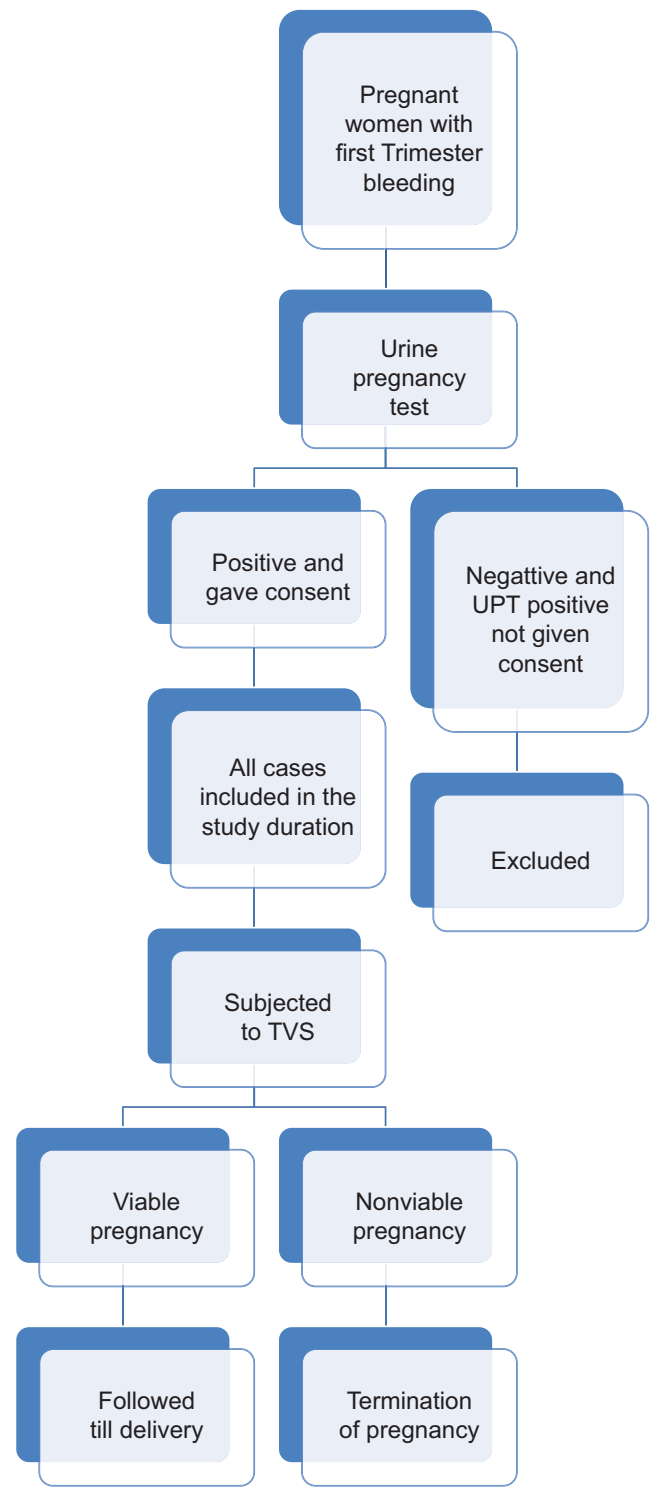

Figure 1: Study procedure 
and 2, hepatitis $\mathrm{B}$ surface antigen, anti-hepatitis $\mathrm{C}$ virus, urine $\mathrm{RE} / \mathrm{MEand} \mathrm{C} / \mathrm{S}$, and ultrasound (USG) for early pregnancy profile.

\section{Statistical analysis}

All data were verified and entered into Microsoft Excel. Data cleaning was done meticulously. Data were analyzed using SPSS version 23. The categorical data or qualitative data were presented by frequency along with percentages. $\mathrm{P}<0.05$ was considered as level of significance.

\section{RESULTS}

The mean age of the study population is $24.053 \pm 5.267$ years, lowest being 18 years and highest being 37 years. Table1 showsthat116 (61.05\%)out of190wereprimigravidaandrest $74(38.95 \%)$ were multigravida. Maximum number of patients, that is, $102(53.68 \%)$, presented a $\mathrm{t} 7$ weeks of gestation. Sixty $(31.58 \%)$ patients were at $7-10$ weeks of gestation and only $28(14.74 \%$ ) of patients belonged to gestational age above10 weeks.

Table 2 shows that 75(39.47\%) had missed abortion, $43(22.63 \%)$ patients had incomplete abortion, and $23(12.10 \%)$ patients resulted complete abortion. Twentyfive $(13.16 \%)$ patients out of 190 had sub-chorionic hemorrhage detected by USG out of which10 (40\%) patients ended up in abortion and $15(60 \%)$ patients continued their pregnancy.

\begin{tabular}{lcc}
$\begin{array}{l}\text { Table 1: Baseline parameters of patients at the } \\
\text { time of admission }(\mathbf{n = 1 9 0 )} \\
\text { Parameters }\end{array}$ & Number & Percentage \\
\hline Parity & 116 & \\
$\quad$ Primigravida & 74 & 61.05 \\
$\quad$ Multigravida & & 38.95 \\
Gestational age & 102 & 53.60 \\
$\quad<7$ weeks & 60 & 31.58 \\
$\quad 7-10$ weeks & 28 & 14.74 \\
$\quad>10$ weeks & & \\
Pattern of bleeding & 158 & 83.16 \\
$\quad$ Spotting & 32 & 16.84 \\
$\quad$ Heavy & & \\
Abortion in previous pregnancy & 73 & 38.42 \\
$\quad$ Yes & 117 & 61.57 \\
$\quad$ No & & \\
\hline
\end{tabular}

\begin{tabular}{lcc}
$\begin{array}{l}\text { Table 2: Distribution of population according to } \\
\text { USG finding }(\mathbf{n = 1 9 0 )}\end{array}$ & Number & Percentage \\
\hline USG findings & 75 & 39.47 \\
\hline Missed abortion & 43 & 22.63 \\
Incomplete abortion & 23 & 12.10 \\
Complete abortion & 08 & 4.21 \\
IUFD & 41 & 21.57 \\
Normal &
\end{tabular}

About $74.21 \%$ had lost pregnancy in the $1^{\text {st }}$ trimester. About $62.10 \%$ of patients underwent dilation and evacuation and manual vacuum aspiration (surgical intervention), $12.10 \%$ of patients who had complete abortion were managed conservatively. About $25.79 \%$ of patients who were continued pregnancy giving tab. folic acid, tab. progesterone, and advising complete bed rest. Among them, 2(1.05\%)patients were given cervical cerclage.

Pregnancy was continued to the $2^{\text {nd }}$ trimester in 49 (25.78\%) patients. Four $(2.10 \%)$ patients had the $2^{\text {nd }}$ trimester abortion and $8(4.21 \%)$ patients had IUFD. Only $37(19.47 \%)$ patients had delivered live babies.

Table 3 shows that $6(16.21 \%)$ had pretermlabor, $2(5.40 \%)$ had PROM, 3(8.10\%) had pregnancy-induced hypertension (PIH), 4(10.81\%) had antepartum hemorrhage (APH), and $22(59.45 \%)$ reached up to term pregnancy. Thirtyseven $(19.47 \%$ ) out of 190 study population had viable pregnancy. Out of 37 viable pregnancies, 2(5.40\%) had early neonatal death, $8(21.62 \%)$ needed NICU admission, $3(8.10 \%)$ suffered from fetal distress, $2(5.40 \%)$ had meconium stained liquor, $3(8.10 \%)$ were intrauterine growth retardation (IUGR), 12(32.43\%)had birth weight $<1.5 \mathrm{~kg}, 22(59.45 \%)$ had birth weight of $\geq 2.5 \mathrm{~kg}$, and rest of neonates, that is, $3(8.10 \%)$ had birth 1.5 to $<2.5$ weight in between. About $24.32 \%$ and $75.67 \%$ had APGAR $<7$ and $>7$ at 1 min, respectively. About $21.62 \%$ and $78.37 \%$ had APGAR $<7$ and $>7$ at5 min, respectively. Table 4

\begin{tabular}{|c|c|c|}
\hline Outcomes & Number & Percentage \\
\hline \multicolumn{3}{|l|}{ Maternal } \\
\hline Pretermlabor & 6 & 16.21 \\
\hline PROM & 2 & 5.40 \\
\hline $\mathrm{PIH}$ & 3 & 8.10 \\
\hline $\mathrm{APH}$ & 4 & 10.81 \\
\hline Term & 22 & 59.45 \\
\hline \multicolumn{3}{|l|}{ Fetal } \\
\hline \multicolumn{3}{|l|}{ Birth weight } \\
\hline$<1.5 \mathrm{~kg}$ & 12 & 32.43 \\
\hline $1.5-<2.5 \mathrm{~kg}$ & 3 & 8.10 \\
\hline$\geq 2.5 \mathrm{~kg}$ & 22 & 59.45 \\
\hline \multicolumn{3}{|l|}{ APGARscore } \\
\hline APGAR<7 (1 min) & 9 & 24.32 \\
\hline APGAR>7 (1 min) & 28 & 75.67 \\
\hline APGAR<7 (5 min) & 8 & 21.62 \\
\hline APGAR>7 (5 min) & 29 & 78.37 \\
\hline \multicolumn{3}{|l|}{ Neonatal complications } \\
\hline IUGR & 3 & 8.10 \\
\hline Meconium stained liquor & 2 & 5.40 \\
\hline Fetal distress & 3 & 8.10 \\
\hline NICU admission & 8 & 21.62 \\
\hline Early neonatal death & 2 & 5.40 \\
\hline \multicolumn{3}{|c|}{$\begin{array}{l}\text { PROM: Premature rupture of membranes, PIH: Pregnancy-induced hypertension, } \\
\text { APH: Antepartum hemorrhage, NICU: Newborn intensive care unit, IUGR: } \\
\text { Intrauterine growth retardation, APGAR: Appearance, pulse, grimace, activity, and } \\
\text { respiration }\end{array}$} \\
\hline
\end{tabular}


shows that 18 patients (48.64\%) delivered vaginally, $17(45.94 \%)$ underwent lower segment cesarean section, and only $2(5.40 \%)$ patients had instrumental delivery (by forceps). Table 5 shows that $158(83.16 \%)$ out of 190 patients presented with spotting of which $58.42 \%$ were aborted and $24.74 \%$ continued pregnancy. Thirty-two $(16.84 \%)$ patients presented with heavy bleeding out of which $30(15.78 \%)$ were aborted and rest of the patients, that is, $2(1.05 \%)$ continued their pregnancy which was statistically significant. Seventy-three $(38.42 \%)$ patients studied had a history of abortion in previous pregnancy of which $65(34.21 \%)$ patients got aborted and rest of the patients continued their pregnancy. One hundred and seventeen $(61.58 \%)$ out of 190 had no history of abortion in their previous pregnancy and $76(40 \%)$ were aborted and $41(21.58 \%)$ continued pregnancy which was statistically significant.

\section{DISCUSSION}

The mean age of the study population in our study was $24.053 \pm 5.267$ years. Yasmin et al., showed that the mean maternal age was $26.53 \pm 6.36$ year. ${ }^{3}$ The present study showed that majority had spontaneous abortion when

\begin{tabular}{lcc}
$\begin{array}{l}\text { Table 4: Distribution of population according to } \\
\text { mode of delivery }(\mathrm{n}=\mathbf{3 7})\end{array}$ & Number & Percentage \\
\hline Mode of delivery & 18 & 48.64 \\
\hline Vaginal delivery & 2 & 5.40 \\
Instrumental delivery & 17 & 45.94 \\
LSCS & & \\
\hline LSCS: Lower segment cesarean section & &
\end{tabular}

threatened abortion occurred at early week of gestation at $<7$ weeks than threatened abortion occurred a bit later gestational age which was statistically significant $(\mathrm{P}=0.000)$. Bleeding prevalence was highest around gestational week

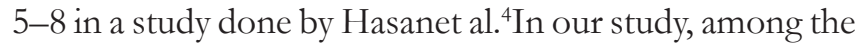
patients presented with the first trimester bleeding, $61.05 \%$ were primigravida and $38.95 \%$ were multigravida which were not statistically significant $(\mathrm{P}=0.321)$. Amirkhani et al., reported that $56.7 \%$ of patients who presented with the first trimester bleeding were primigravida and $43.3 \%$ were multigravida which are similar to our study. ${ }^{5} \mathrm{Kanmaz}$ et al., reported nulliparity $37.5 \%$ and multiparity $62.5 \%$ among the pregnant mothers with threatened abortion. ${ }^{6}$ Lewis et al., showed that the risk of first trimester vaginal bleeding was more in multigravida. ${ }^{7}$ Majority $(83.16 \%)$ patients of the present study presented with spotting. Only $16.84 \%$ of patients had heavy bleeding.

There was a significant correlation between abortion in the current pregnancy and the history of previous pregnancy $\operatorname{loss}(\mathrm{P}=0.000)$ seen in our study. Bhattacharya et al., showed that an initial abortion is associated with a higher risk of obstetric complications in next pregnancy. ${ }^{8}$ Lewis et al.,found that $30.67 \%$ of patients with the first trimester vaginal bleeding had a history of previous abortion. ${ }^{7}$ Similar findings were also noted by Hossain et al., and Hackneyetal. ${ }^{9,10}$

In our study, abortion occurred in $74.21 \%$ of patients with a history of the first trimester vaginal bleeding. Amirkhani et al., showed that only $30 \%$ had abortion and $70 \%$ continued pregnancy. ${ }^{5}$ Talwer et al., had reported $18 \%$ spontaneous abortion. ${ }^{11}$ Yakistiran et al., showed $11.7 \%$,

\begin{tabular}{|c|c|c|c|}
\hline $\begin{array}{l}\text { Patient } \\
\text { particulars }\end{array}$ & $\begin{array}{l}\text { Patients who } \\
\text { aborted (\%) }\end{array}$ & $\begin{array}{l}\text { Patients who continued } \\
\text { pregnancy }(\%)\end{array}$ & P-value \\
\hline \multicolumn{4}{|l|}{ Age (years) } \\
\hline$<20$ & $30(15.78)$ & $29(15.26)$ & P-value (by Pearson \\
\hline $21-30$ & 93 (48.95) & $7(3.68)$ & Chi-square test) 0.0001 \\
\hline $31-35$ & $14(7.37)$ & $12(6.32)$ & \\
\hline$>35$ & $4(2.11)$ & $1(0.5)$ & \\
\hline Total & $141(74.21)$ & 49 (25.79) & \\
\hline \multicolumn{4}{|l|}{ Gravida } \\
\hline Primigravida & $89(46.84)$ & $27(14.21)$ & P-value-0.321 \\
\hline Multigravida & $52(27.37)$ & $22(11.58)$ & \\
\hline \multicolumn{4}{|c|}{ Gestational age at presentation } \\
\hline$<7$ weeks & $101(53.16)$ & $1(0.53)$ & P-value-0.0000 (By \\
\hline $7-10$ weeks & $26(13.68)$ & $34(17.89)$ & Pearson Chi-square test) \\
\hline >10 weeks & $14(7.37)$ & $14(7.37)$ & \\
\hline \multicolumn{4}{|c|}{ Pattern of bleeding } \\
\hline Spotting & $111(58.42)$ & $47(24.74)$ & P-value-0.001 (Chi-square \\
\hline Heavy & $30(15.78)$ & $2(1.05)$ & test) \\
\hline \multicolumn{4}{|c|}{ Abortion in previous pregnancy } \\
\hline Yes & $65(34.21)$ & $8(4.21)$ & P-value-0.0000(Pearson \\
\hline No & $76(40)$ & $41(21.58)$ & Chi-square test) \\
\hline
\end{tabular}


who experienced bleeding in the first trimester terminated their pregnancies with spontaneous abortion while $88.3 \%$ of pregnancies continued after 24 weeks' of gestation. ${ }^{12}$ Lewis et al., showed $67.67 \%$ abortion among patients with the first trimester vaginal bleeding. ${ }^{7}$ According to our study, abortion occurred in $93.8 \%$ (30 of 32) of patients with heavy bleeding and $70.25 \%$ (111 of 158) patients with spotting which is statistically significant $(\mathrm{P}=0.001)$. Hasan et al., reported $24 \%$ of women with heavy bleeding experienced miscarriage. ${ }^{4} \mathrm{Gracia}$ et al., also found that heavy bleeding was strongly associated with miscarriage which is matching with the present study. ${ }^{13}$

Our study showed PROM $5.40 \%$ and preterm labor $16.21 \%$ among patients with a history of first trimester bleeding. The finding of the study done by Talwar et al., where pre-labor rupture of membranes was seen in $20 \%$ of patients and $21 \%$ had preterm labor. ${ }^{11}$ Kanmaz et al., reported preterm labor in $6.2 \%$ of patients. ${ }^{6}$ The incidence of preterm PROM was significantly higher in women whose pregnancy was complicated by the first trimester bleeding (OR 1.78, 95\% CI 1.28, 2.48) found in a study by Saraswat et al. ${ }^{14} \mathrm{Amirkhani}$ et al., showed PROM in 8.3\% and preterm labor in $25 \%$ of patients with a history of first trimester bleeding. ${ }^{5}$

We found IUGR in $8.10 \%$ of patients whereas Amirkhani et al., reported IUGR 5\%. ${ }^{5}$ Davari-Tanha etal., reported an increased risk for IUGR in the case group. 15 Incidence of intrauterine fetal death in our study was $4.21 \%$.Kanmaz et al., showed incidence of still birth as $2 \%{ }^{6}$ and Amirkhani et al., showed IUFD of $1.7 \%{ }^{6}$

Among the pregnancy complications, $10.81 \%$ of patients had antepartum hemorrhage in our study. Saraswat et al., reported that APH was more among in those with threatened miscarriage. ${ }^{14}$ Kanmazet al., showed $1.23 \%$ of antepartum hemorrhage ${ }^{6}$ and Amirkhani et al., reported placenta abruption in $13.3 \%$ of patients. ${ }^{5}$ In our study, $8.10 \%$ of patients had PIH. According to Saraswat et al., incidence of PIH, preeclampsia, or eclampsia was not significantly altered by bleeding in the first trimester. ${ }^{14}$ Kanmaz et al. reported preeclampsia in $3.8 \%$ of patients. ${ }^{6}$

Regarding neonatal outcome, we found $40.54 \%$ baby born with low birth weight. Kanmaz et al., reported incidence of low birth weight as $15.8 \%$. ${ }^{6}$ In our study, $21.62 \%$ of baby needed NICU admission. About $11 \%$ of neonates were admitted in NICU in the study of Kanmaz et al. ${ }^{6}$ The current study showed that rate of vaginal delivery and cesarean section was almost same (48.64\%vs. 45.94\%). Most of the preterm pregnancies were delivered vaginally. Saraswat et al., showed that the first trimester bleeding did not influence the mode of delivery. ${ }^{14}$

\section{Limitations of the study}

Apart from small sample size, our study could not evaluate the relation between threatened abortion and congenital malformation of the baby. Long-term follow-up and prognostic assessment were also could not be done here. As most of the people in the study were from similar ethnic background, it could not represent the entire population of India which has a large ethnic diversity.

\section{CONCLUSION}

The risk of adverse maternal outcomes suchas abortion, preterm rupture of membranes, hypertension in pregnancy, antepartum hemorrhage, and preterm labor is increased in mothers with the first trimester vaginal bleeding. Similarly, adverse fetal outcomes such as low birth weight, IUFD, fetal distress, and IUGR are also increased.

\section{ACKNOWLEDGMENT}

We would like to thank all the women participated in this study and all concerned staffs in the Department of Gynecology and Obstetrics, R.G. Kar Medical College, for their cooperation.

\section{REFERENCES}

1. Chung TK, Sahota DS, Lau TK, Mongelli JM, Spencer JA and Haines CJ. Threatened abortion: Prediction on viability based on signs and symptoms. Aust NZJ Obstet Gynaecol. 1999;39(4):443-447.

https://doi.org/10.1111/j.1479-828x.1999.tb03129.x

2. Uerpairojkit B, Tannirandorm Y, Manotaya S, Somprasit C, Charoenvidhya $D$, Wacharaprechanont $T$, et al. Sonographic findings in clinically diagnosed threatened abortion. J Med Assoc Thai. 2001;84(5):661-665.

3. Yasmin $\mathrm{H}$, Mohsin $\mathrm{H}$ and Korejo R. Preterm deliveries in women presenting with threatened abortion. J Surg Pak. 2015;20(1):5-9.

4. Hasan $R$, Baird $D B$, Herring $A H$, Olshan $A F$, Funk $M L$ and Hartmann KE. Association between first-trimester vaginal bleeding and miscarriage. Obstet Gynecol. 2009;114(4):860-867. https://doi.org/10.1097/AOG.0b013e3181b79796

5. Amirkhani Z, Akhlaghdoust M, Abedian M, Salehi GR, Zarbati N, Mogharehabed $\mathrm{M}$, et al.Maternal and perinatal outcomes in pregnant women with first trimester vaginal bleeding. J Fam Reprod Health. 2013;7(2):57-61.

6. Kanmaz AG, Inan AH, Beyan $E$ and Budak $A$. The effects of threatened abortions on pregnancy outcomes. Ginekol Pol. 2019;90(4):195-200.

https://doi.org/10.5603/GP.a2019.0035

7. Lewis $P$, Anand $A R$ and Pimple P. A study on fetomaternal outcome in first trimester bleeding per vagina. Glob J Res Anal. 2014;3(11):55-57.

8. Bhattacharya S, Townend J, Shetty A, Campbell D and Bhattacharya S. Does miscarriage in an initial pregnancy lead to adverse obstetric and perinatal outcomes in the next continuing pregnancy? BJOG. 2008;115(13):1623-1629. 
https://doi.org/10.1111/j.1471-0528.2008.01943.x

9. Hossain R, Harris T, Lohsoonthorn V and Williams M. Risk of preterm delivery in relation to vaginal bleeding in early pregnancy. Eur J Obstet Gynecol Reprod Biol. 2007;135(2):158-163. https://doi.org/10.1016/j.ejogrb.2006.12.003

10. Hackney DN and Glantz JC. Vaginal bleeding in early pregnancy and preterm birth: Systemic review and analysis of heterogenesity. J Matern Fetal Neonatal Med. 2011;24(6):778-786. https://doi.org/10.3109/14767058.2010.530707

11. Talwar P, Priya $\mathrm{H}$ and Chaya $\mathrm{D}$. The outcome of pregnancy in patients with threatened abortion. J Evid Based Med Healthc. 2015;2(42):7492-7498.

https://doi.org/10.18410/jebmh/2015/1012
12. Yakıştıran $B$, Yüce $T$ and Söylemez F. First trimester bleeding and pregnancy outcomes: Case-control study. Int J Womens Health Reprod Sci. 2016;4(1):4-7.

13. Gracia C, Sammel M, Chittams J, Hummel A, Shaunik A and Barnhart K. Risk factors for spontaneous abortion in early symptomatic first-trimester pregnancies. Obstet Gynecol. 2005;106(5):993-999. https://doi.org/10.1097/01.AOG.0000183604.09922.e0

14. Saraswat L, Bhattacharya S, Maheshwari A and Bhattacharya S. Maternal and perinatal outcome in women with threatened miscarriage in the first trimester: A systematic review. BJOG. 2010;117(3):245-257.

https://doi.org/10.1111/j.1471-0528.2009.02427.x

\section{Authors Contribution:}

MG- Data collection, interpreted the results, review of literature, and manuscript preparation; SS- Concept of study and revision of manuscript; AKM- Concept and design of the study, prepared first draft of manuscript, revision of manuscript, and prepare final manuscript; AN- Coordination, preparation of manuscript, and support.

Work attributed to:

R.G.Kar Medical College, Kolkata - 700004, West Bengal, India

Orcid ID:

Dr. Mousumi Ghosh - (D https://orcid.org/0000-0002-8513-4635

Dr. Aparna Khan Mandal - (iD https://orcid.org/0000-0002-3794-4625

Dr. Shelley Seth - it https://orcid.org/0000-0003-2964-0717

Dr. Animesh Naskar - (D https://orcid.org/0000-0002-9319-6465

Source of Support: Nil, Conflict of Interest: None declared. 